\title{
Preschool Piano Educator's Comprehensive Capacity Development in the Era of Intelligent Keyboards
}

\author{
Li Meizhuan", Li Jia ${ }^{2, *}$ \\ ${ }^{1}$ Yuncheng University, Shanxi, China \\ ${ }^{2}$ College of Music, Shanxi Normal University, Shanxi, China \\ *Corresponding author: lijia@sxnu.edu.cn
}

\begin{abstract}
This study is intended to assess the preschool piano educator's comprehensive capacity development in the era of intelligent keyboards. Consequently, the impact of learning to play the piano on a child's development has begun to be studied. However, not all keyboards are created equal, and there is reason to assume that the discrete control provided by standard MIDI keyboards puts unwanted constraints on today's digital instruments. The distinctive sounds of most of the instruments listed in this article would be impossible to achieve with discrete onsets and releases. This study utilized the Descriptive Correlational method as its design and methodology that describes the phenomenon, condition, and situation of preschool piano educators' comprehensive capacity development in the era of intelligent keyboards. Moreover, the quantitative research method uses statistical, mathematical, or computational techniques to investigate observable phenomena systematically. The results found challenges in the preschool piano educator's comprehensive capacity development in the era of intelligent keyboards. There is no significant relationship between assessing the preschool piano educator's comprehensive capacity development in the era of intelligent keyboards and when grouped according to profile.
\end{abstract}

Keywords: Intelligent Keyboards, Piano Educator, Piano, Capacity Development

\section{Introduction}

Education is the most important phenomena utilized to equip people with desirable behaviors and attributes, as well as to create temperamental genetic elements. It is considered that civilizations pass on their distinguishing features to future generations in line with traditions and customs, ensuring that they are learned. The primary aspect and one of the earliest steps of learning throughout this process is attentiveness. The human data processing system relies heavily on attention (Caglar and Koruc, 2006). While the Turkish Linguistic Society Dictionary (2005) defines attention as concentrating one's thoughts and emotions on something. In the dictionary of psychology, vigilance is defined as the ability to ignore some perceptional functions, thoughts, sensual entries, cognitive stimuli while choosing some of these and focusing on them, thus perceiving chosen stimulants more clearly and voluntarily controlling and directing all of these processes (Budak, 2000). Attention and perception are required in order to notice stimuli received by sense organs during sensual registry and transfer them to shor (Kurtuldu, 2012).

Attention regulation, according to Anderson (2002), emerges in infancy and grows fast throughout early childhood. Cognitive flexibility, targeting, and data processing, on the other hand, begin to develop between the ages of 7-9 and are completely developed by the age of 12 . According to Piaget (as described in Ulugbay (2013)), children's intellectual growth is accelerated, particularly between the ages of 2 and 7 years. This circumstance had an impact on the selection of 7-12-year-old children for the sample, as well as the assumption that music instruction may play an important role in the development of children's attention level and abilities. This is due to the fact that music education fosters the development of children's abilities such as analysis, synthesis, coordination, and creativity by encouraging intentional thinking. Today, music education experts emphasize that musical instrument training, which is an important aspect of music education, is critical for children's personality development, emotional and skill development, and learning to be self-confident, patient, and self-disciplined, as well as having long-term attention skills. Furthermore, active participation in music, according to Hallam (2015), has a considerable influence on brain structure and function.

According to Hallam (2015), correlation studies show that there are relationships between musical 
activities and various literacy skills such as verbal and auditory working memory, spatial reasoning and mathematical performance, intellectual development, creativity, emotional intelligence, and so on. After the 1950s, the value of early piano instruction grew. Because musicians did not master child development and child development experts did not master music education, there was no agreement between musicians and child development experts on the appropriate time to begin piano instruction and the timetable that should be followed. However, throughout time, it has been clear that the sooner a kid begins music instruction, the better the outcome, and a philosophy of music education has emerged.

As a consequence, the impact of learning to play the piano on a child's development has begun to be studied (Minina, 2012). Melodies with several rhythms written in two staves in distinct clefs (treble clef - bass clef) must be performed properly and accurately while playing the piano, which is a popular instrument in Turkey. These difficult challenges need superb eye, hand, and foot coordination. Aside from these psychomotor abilities, several tasks, such as polyphonic hearing, may be performed simultaneously while playing the piano. Complex activities are thought to help children's brains improve data processing skills. It is also claimed that playing the piano requires constant concentration and focused. According to a study conducted by Shaw and Rauscher (as cited in Ulugbay (2013)), playing the piano is the most functional way to improve cognitive structure that affects preschool children demonstrating high skills in mathematics and science; and that music education, particularly piano education until the age of 12 , is an activity requiring functions that mathematics and chess entail, such as high brain functions.

Pavlov's (2008) research focuses on the significance of instrument education. In one of his studies, there were 41 children who played an instrument (14 playing flute and 27 playing piano) and 25 children who did not. All of the youngsters were between the ages of 6 and 7, and their physical and cognitive skills were comparable. Following 7-8 months of instruction, all of the children had six different neuropsychological tests to assess their attention and cognitive ability. Those who played an instrument showed more progress than children who did not. When compared to the other children, those who played the flute had a better sense of space. Children who played the piano improved their verbal thinking, verbal memory, logical intelligence, cognitive, and psychomotor abilities. Permiakova and Tkachenko (2016) found comparable findings in a study of youngsters who had just begun to play the piano. Their research, which was conducted in Ekaterinburg, included 50 youngsters, 26 of whom did not play any instrument and 24 of whom had begun to take piano lessons. After a year, these youngsters underwent the necessary exams at Moscow State University's Neuropsychology Laboratory. Children who played the piano showed greater advances in cognitive and psychological abilities, as well as 1.5 times faster motor development. Permiakova and Tkachenko (2016) conducted a second experiment on 10 male youngsters with hyperactivity and attention deficit disorder in the second portion of this investigation.Five of them played the piano, while the other five did not. Both groups took the same exams as the prior groups, including attention, memory, and cognitive ability. After a year, children who played the piano performed much better than children who did not play the piano. Piano lessons are highly advised for youngsters who have hyperactivity or attention deficit disorder. The preceding research demonstrates the advantages of music and piano instruction for brain development. Demirova's (2008) study is another unusual study that shows the advantages of piano instruction for attention skills. Demirova (2008) shown in her research that piano instruction improves elementary school children's attention abilities.

Furthermore, according to Kuscu (2010), musical activities such as the Orff Schulwerk method increase preschool children's attention abilities greatly. According to the worldwide and national research described above, studies suggest that music instruction, especially piano education, has a substantial impact on children's development. Attentive study and long-term focus are two crucial aspects of playing the piano, which is one of the instruments that may be learned at a young age. Every school, education system, and curriculum places equal emphasis on attention. In this context, Demirova (2008) detects a link between playing the piano and attention, which is regarded as a bridge or a tool between the students' musical progress and their performance on the piano.

\section{Theoretical Framework}

Developmental theories have an influence on how instructors think and educate their pupils. Teachers are often unfamiliar with the names or founders of these beliefs, yet they are nevertheless influenced. Because of the effect instructors have on their pupils, it is critical to grasp these notions while working with children. Unfortunately, in this small study, it would be impossible to present a thorough assessment of even the most important developmental theories influencing the keyboard 
educational field. For this discussion, a basic overview of the methodologies used to classify the various developmental theories, as well as Piaget's stages of cognitive development, should serve. It is important to remember that "learning is a complicated phenomenon, and our knowledge of learning has evolved through time." Our understandings of learning are embedded in the historical and epistemological traditions that give them significance.

There are several types of developmental theories. MENC examines two of these in their guide Research on Music Learning. The first technique is divided into five categories: conceptual analysis, behavioral analysis, constructivist analysis, computational analysis, and connectionist analysis. 13 The second technique classifies theories according to the many learning styles: verbal information, intellectual skills, physical skills, attitudes, and cognitive strategies. 14 It is critical to recognize that "various perspectives on music learners are based on distinct assumptions, and these assumptions build music learners as persons in a certain manner." 15 While the commonalities between the various ideas are helpful, the discrepancies may be more so. Each distinction highlights a feature that the other hypotheses overlooked. Jean Piaget's phases of cognitive development continue to have power in educational circles. Jean Piaget discovered four developmental phases.

Because they are broad categories, they assist to provide a large picture of a typical child's growth. The first stage, known as sensorimotor, lasts from before birth to roughly two years of age and is characterized by sensory experience and reflexes. Between the ages of two and seven years, children enter the preoperative period. The youngster has only tangible comprehension and irreversible reasoning at his disposal. Children struggle to grasp and learn when employing non-concrete tactics. In this period, verbal teaching is not regarded the ideal mode of training; rather, hands-on learning is recommended. Children also struggle with beginning at the end of a problem and moving backwards. When children reach the third stage, known as concrete operational (between the ages of seven and eleven), they have reversible reasoning and can think from the standpoint of another person. Teachers should be mindful that children at this stage still have difficulty estimating how long it will take them to learn or recall knowledge. The last stage is formal operational, which begins at the age of eleven and lasts till adulthood. During this period, toddlers learn to think abstractly and theoretically.

In this era, physical activities are one of the finest methods for youngsters to learn. Physical activities, fortunately for piano instructors, should be an intrinsic element of a child's instruction throughout the time limit allotted for novice pupils. Learning to play the piano is a physical as well as a mental endeavor. The ability of a youngster to comprehend ideas physically influences his ability to understand things intellectually, and vice versa. "Skilled movement requires skillful reasoning. Young children often learn by exploration and are generally active. These attributes, together with a child's natural drive to play, establish the groundwork for discovering new and interesting ways to learn."

The majority of research on the influence of music engagement on social and personal development is based on self-report, either via questionnaires or interviews. It has gotten less attention than the influence on intellectual development and accomplishment, despite the fact that the impacts on success may be mediated in part by a rise in social and cultural capital. Broh (2002), for example, found that kids who engaged in musical activities communicated more with their parents and professors, and that their parents were more willing to interact with their friends' parents. She concluded that these social advantages were likely to boost children's self-esteem, which in turn increased drive and self-efficacy. According to a research conducted by the Norwegian Research Council for Science and Humanities, there is a link between musical ability and strong desire, which leads to a higher possibility of academic achievement (Lillemyr, 1983).

Positive self-perception, cognitive competence score, self-esteem, and interest and engagement in school music all had strong relationships. Whitwell (1977) reached similar findings, arguing that creative engagement in music increases self-image, self-awareness, and positive self-attitudes. Similar results have been seen with urban black middle school kids (Marshall, 1978) and low-income youngsters.

It seems that success in music might boost overall sentiments of confidence and self-esteem, improving desire for general study. Increasing the amount of classroom music in the curriculum did not have a negative effect on language and reading skills in Switzerland, despite a reduction in time in these lessons, and there was an increase in social cohesion within the class, greater self-reliance, better social adjustment, and more positive attitudes in the children. These impacts were especially noticeable among low-ability, dissatisfied students (Spychiger, et al., 1993).

According to Harland (2000), the most common overall impacts on students gained from involvement in the arts in school were connected to personal and social development. There were 
perceived impacts in music linked to other people's awareness, social skills, well-being, and transfer effects. Variations in reaction across schools were connected to the level of musical knowledge and experience brought to the school curriculum by the students. Some students saw the benefits of music classes as listening to music and developing musical skills, while others cited the sheer fun and therapeutic nature of music, how it gave them confidence to perform in front of others, how it facilitated group work, and how it taught them to express themselves.

Those who played instruments reported higher self-esteem and a stronger feeling of identity. Tolfree and Hallam (in preparation) also documented a sense of accomplishment, enhanced confidence, and the availability of an alternate method of articulating sentiments in regard to playing an instrument for youth aged 9-17 in 18. They also spoke about how much fun it was to play with their pals and how frustrated they were when they couldn't get things perfect when they practiced alone. In the United States, two studies looked at the perceived advantages of school band involvement. Achievement, gratitude, discipline, pleasure, active engagement, and expanding relationships were among the rewards (Brown 1980). 95 percent of non-band participants' parents stated that band offered educational advantages not available in other classes, and 78 percent agreed that band was more educational than extra-curricular activities.

Band directors discussed the benefits of discipline, teamwork, coordination, skill development, pride, lifetime skills, accomplishment, cooperation, self-confidence, sense of belonging, responsibility, self-expression, creativity, performance, companionship, character and personality development, selfesteem, social development, and enjoyment in general terms. In a follow-up research (Brown, 1985), 91 percent of non-band parents, 79 percent of non-band students, 90 percent of drop-out band parents, and 82 percent of drop-out band students agreed that being in a band increases self-esteem, confidence, and a feeling of success.

Similarly, peripatetic instrumental teachers working in schools in the United Kingdom reported significant benefits of learning to play an instrument, including the development of social skills, the acquisition of a love and enjoyment of music, the development of teamwork, the development of a sense of achievement, confidence, and self-discipline and the development of physical co-ordination (Hallam and Prince, 2000). Participating in the extra-curricular preparation and production of a school play has been found to encourage the building of friendships with like-minded persons and to contribute to social life by increasing non-participants' knowledge of the show. Despite the time commitment, which often interfered with other activities, such engagement boosted students' confidence, social networks, and feeling of belonging. Involvement in group music activities in high school has also been demonstrated in research in the United States to assist people learn to support one another, sustain commitment, and connect together for collective objectives.

Reflecting on previous and current group music making activities, university music students reported benefits such as pride in being an active contributor to a group outcome, developing a strong sense of belonging, gaining popularity and making friends with 'like-minded' people, social skill enhancement, and the development of a strong sense of self-esteem and satisfaction. Students also reported improved personal abilities that aided in the development of personal identity and selfachievement, self-confidence, and intrinsic drive.

A subsequent research with non-music students who had previously participated in musical groups found comparable advantages, but there was a stronger focus on the influence of group music production on the self and personal growth. Students indicated that participating in music actively helped them improve life skills such as discipline and attention, as well as offered an outlet for relaxation during stressful academic times. In a survey of 84 members of a collegiate choral society, $87 \%$ said they had benefited socially, $75 \%$ said they had benefited emotionally, and $49 \%$ said they had benefited spiritually. Meeting new people, feeling more cheerful, and being spiritually elevated were all mentioned (Clift and Hancox, 2001). Social interactions and the building of trust and respect are critical for the operation of small musical ensembles Rehearsals must be anchored by strong social frameworks for long-term success since interactions are often typified by conflict and compromise relating mostly to musical content and its coordination, while some interactions are of a more personal nature. Personal relationship seems to be more significant in smaller groups. Music has an important role in the formation of self-identity throughout adolescence.

In the United Kingdom, about three hours per day is usual (North et al., 2000). They do this to pass the time, to relieve boredom, to release stress, and to divert themselves from their troubles. When young people are disturbed or lonely, music is considered as a source of comfort, working as a mood regulator and aiding in the maintenance of a sense of connection and community Its impact on 
emotions at this time may be significant. It is also utilized to meet the demands of impression management. Adolescents may maintain positive self-evaluations by participating in social comparisons and portraying their own peer groups more favourably than other groups in their network. This procedure is aided by music. Music has the potential to promote emotional sensitivity in addition to enhancing personal and social abilities. They discovered a link between the capacity to recognize emotions in classical piano music performances and measures of emotional intelligence that asked participants to identify, analyze, reason about, and control emotions using hypothetical situations. The two were substantially linked, suggesting that identifying emotion in music performance requires some of the same abilities as daily emotional intelligence. While it is clear from the research outlined above that music can have very positive effects on personal and social development, it should be noted that the research has largely focused on those who are currently involved in active music, leaving out those who have not found it an enjoyable and rewarding experience. The quality of the teaching, the extent to which individuals experience success, whether engaging with a specific type of music can be integrated with existing self-perceptions, and whether the overall experience is positive will all contribute to whether there is a positive impact on social and personal development.

Normal children between the ages of five and ten are in the preoperational stage of development, which necessitates the use of concrete examples and analogies. While the youngster understands a stepby-step learning process, he is generally only concerned with the next step and pays little attention to the previous ones. This implies that unless he breaks it down into stages, he will have difficulty thinking about notes, fingering, dynamics, pedaling, phrasing, and voice all at the same time while practicing. He cannot contemplate the following step until the first step is accomplished, at least not without practice.

\section{Review of Related Literature and Studies}

Realizing the abilities that trained musicians and pianists have is important in forming the goals for teaching children. It is only by having clear goals in mind that teachers and students have the ability to work toward those goals. Musicians need to be able to recognize and integrate input from their visual, auditory, and physical senses. This ability is called cross-model perception. It starts to develop in infancy and "is likely to play an important role for the perception of musical expression." Pianists need to take the visual information from the placement of his hand, from sheet music, aural input from their instrument, and from the physical input from their fingers, hands, and feet. Each type of input needs to be compared with and matched to the other types.

A study by Janeen Leohr and Caroline Palmer examined the influence auditory and kinetic/motor information had on pianists' abilities to perform a musical melody to a metronome. Leohr and Palmer found that certain types of input can only inform certain processes. The information needed for a pianist to control her fingers comes from two sources: motor information and auditory information that is combined with motor information. Auditory input alone did not give enough information to change finger motion trajectories. In other words, if a pianist were for some reason unable to process the motor information from her hands and only had the aural input, she would be unable to change the speed and direction of her playing. This is thought to be "due to biomechanical constraints of coupling between fingers."

In contrast, auditory information had the most effect upon a pianist's ability to synchronize a melody with a metronome. While auditory and kinetic information inform different parts of music performance, these different parts are not isolated. Although auditory information is not the largest factor in changing the trajectories of a pianist's fingers, the pianist would not know that the trajectories would need to be changed without the auditory feedback. The trajectories of the fingers make the sound and the sound informs the next movements. These movements, whether gross or fine motor, are complex and require skills. These skills have to be learned and remembered. Avi Karni et al. found that, "many instances of skill learning can be strongly dependent on simple physical attributes of the stimulus presented in training a perceptual task or on factors such as the specific effector organ's positions, trajectories, and sequence of trajectories experienced in motor training."

Playing the piano falls under this type of learning and involves complex motor routines. "Such skillful movements consist of a highly complex sequencing ability that requires precise temporal adjustments, and along these lines it has common characteristics with language performance. "The feedback must be immediate for the performer to make the correct adjustments. To learn anything, whether it is cognitive or physical, it is important to remember that there are two types of memory: 
declarative and procedural. Declarative memory is focused on facts and particulars, while procedural memory is concerned with how to do something.

Learning the specifics of a piece of music, such as notes, rhythms, and pedaling, involves declarative memory, while knowing how to play the music is a type of procedural memory. Since learning a piece is based on declarative memory, it is also linked with cognitive abilities. Each piece has a different content from other pieces. The content of notes, rhythms, and dynamics is remembered cognitively. Procedural memory is more closely linked to motor abilities. While each piece has different sequences of motor movement that require declarative memory, the actual motor skills are learned over time by studying multiple pieces. The motor movements used at the piano are based on the pianist's mental perceptions. It is believed that rhythmic grouping is what "helps underscore the impulse motion of tones on weak beats to progress toward tones on strong beats" for both performers and listeners.

Grouping individual notes together to form a phrase is very similar to how individual letters are grouped together to form words. If a reader were able only to process one letter at a time, his reading would be slow and jerky. Likewise, a pianist who is only able to process one note or beat at a time would only be able to play jerkily and unmusically. When a pianist is sight-reading, or at the early stages of learning a piece, it is likely that the learned motor skills are not optimal for performance because of the pianist's limited perception. Only after the pianist has developed an informed perception of the piece can the perception be optimal for a performance. The understanding of the requirements of a piece changes as the pianist learns more about the piece. There is increasing evidence that a person's "perception of the rhythmic grouping organization of music notation does have a direct effect on the formation of motor patterns in piano playing."

A study of a group of sixteen pianists in Germany who were either amateurs or professionals found that "how one perceives a music score - by single notes, articulated motivic patterns, or by the metered pulse-beat grouping - is reflected in the organization of motor patterns especially in wrist motions." Without the rhythmic grouping, the feel of the pulse is lost. If a pianist does not see or understand the rhythmic pattern, he cannot hope to be able to play it. When learning motor motions for music, both hemispheres of the brain are able to store the information. The interesting part of learning motor motions is the communication between the two hemispheres of the brain. When motor movement and rhythmic grouping is learned using the dominant hand and brain hemisphere, the information is easily transferred to the non-dominant hand and brain hemisphere.

This was the same for all pianists in the study, regardless of which hand was dominant. For teaching children, this might mean that the teacher should have a left-handed student learn a motor motion with her left hand before learning it with her right hand. For example, when teaching scales, the teacher might want to start with the left-hand fingering instead of the right as is typical. The strong connection between the physical action of producing music and the mental cognition of music can also be found in music notation. Sergent et al. performed a study that looked at the neural network behind the understanding of music notation. They found that when reading and listening are combined, more areas of the brain are activated. They concluded that the symbol and sound become linked together in the brain when the pianist physically makes the sound.

Understanding music notation requires that the aural sound of the note be connected with the visual representation on paper. This is done by physically playing the note to produce the sound while focusing on the visual representation. It is the physical action that connects the aural to the visual. When teaching younger students, then, it is important to have the student play the note when saying the note name and looking at a flashcard or staff paper multiple times. While a majority of practice for musicians is physical, there is also the concept of mental practice by way of auditory imagery or mental hearing. Auditory imagery is the ability to hear music in the mind's ear without any instrument present to make that sound. For beginners, this ability is only vague. It might be that the piece reminds them of a color, place, or a story. Beginners take that idea and try to translate it into their performance. After much practice, the skill evolves into the ability to hear the whole piece from beginning to end and to change according to will.

Many famous musicians and pianists have used this technique, including Beethoven, Mozart, Schumann, Gould, Horowitz, and Rubinstein.35 By studying musicians with this ability, researchers have found that the same parts of the brain are used in mental practice as they are in physical practice.36 This is one of the main reasons why auditory imagery is so practical for musicians. It gives the ability to practice when the instrument, like the piano, is not available. Auditory imagery is linked with musical perception. 
Without the ability to mentally hear the music, which is what auditory imagery provides, a musician is handicapped in her ability to perceive how the music she is playing should sound. What may come as a surprise is that auditory imagery is not dependent on the primary auditory region of the brain. Instead, auditory imagery uses all four lobes and both hemispheres of the brain. 38 The use of different areas of the brain was found to be more pronounced when the musicians were familiar with the music.39 One reason for this may be due to many musicians learning auditory imagery by becoming familiar with a piece of music and then recalling it to mind.40 Also, since auditory imagery is linked to the physical action of creating the sound, the effect on the brain would be stronger if there had actually been physical action while originally learning the piece.

When children walk into their first piano lesson, most have already had years of experience listening and moving to music. Depending on their background, they might be familiar with any number of genres, including pop, rock, country, jazz, and classical. Not only do children have a familiarity with different genres of music, but there is also increasing evidence that before the age of five, children have an understanding of pitch, melody, harmony, and rhythm. Most of the time they do not have the vocabulary to explain what they know, nor how they know these musical concepts, but the window of opportunity seems to open before the typical starting age for music lessons. It is important for teachers of elementary students to understand the abilities that children already possess before lessons.

There have been studies that show infants as young as six months have the ability to perceive small pitch differences. "A study with American infants demonstrated the ability of 6-month-old infants to recognize single tones that were played out of tune in Western (major/minor) and non-Western scales (Japanese pelog scale)." It is around the same time frame that infants learn to distinguish vowels and consonants of their mother tongue in contrast to other languages. "Infants are also capable of distinguishing several short melodies with the melodic contour as the most important distinguishing feature." Infants also seem to have a sense of different keys by being able to tell when a familiar tune is played once and then played again transposed.

There have been numerous studies dealing with the abilities of infants to recognize rhythm. Active and passive movement, especially head movement, has been linked to the development of meter perception. Even with these studies, it seems that the concept of rhythm seems to develop more slowly. This may be because the conception of duration is dependent of the development of the neocortex.46 "Regular meter in singing first becomes noticeable during the second year of life, first in very short then in increasing longer segments." While infants have shown the ability to recognize pitch, melodic contour, and rhythms, the first year of life merely opens the window of opportunity. Evidence shows that the window of opportunity might extend all the way into the teenage years, although the optimal period for musical aptitude seems to be around the age of nine.

\section{Presentation, analysis and interpretation of data}

This chapter presents the analysis and interpretation of the data. They were presented in tabular form in order to give a clear picture of what has been gathered in the survey questionnaire.

\subsection{Assessment of the Challenges of participants in assessing the preschool piano educator's comprehensive capacity development in the era of intelligent keyboards}

\subsubsection{Understanding of the objectives}

Table 1 Understanding of the objectives

\begin{tabular}{|l|l|l|}
\hline UNDERSTANDING OF THE OBJECTIVES & Mean & $\begin{array}{l}\text { Verbal } \\
\text { Interpretation }\end{array}$ \\
\hline 1. The objectives are too broad & 3.59 & Strongly Agree \\
\hline 2. The objectives are too vague or not easy to understand & 3.53 & Strongly Agree \\
\hline 3. There are no specific objectives indicated & 3.48 & Strongly Agree \\
\hline 4. There are too many objectives included & 3.61 & Strongly Agree \\
\hline 5. The objectives are not aligned with our current lesson & 3.57 & Strongly Agree \\
\hline TOTAL & $\mathbf{3 . 5 6}$ & Strongly Agree \\
\hline
\end{tabular}

3.25-4.00 Strongly Agree; 2.50-3.24 Agree; 1.75-2.49 Disagree; 1.00-1.74

Table 1 represents the assessment of the challenges in modular learning in terms of understanding of the objectives. It shows that they are strongly agreed on the statements above with a weighted mean 
of 3.56 .

A piano lessons objective specifies a specific, observable behavior, skill, or action in small, discrete pieces. Piano lessons objectives can be viewed as the building blocks or tasks that lead students to mastery of a course objective. Modular teaching is concerned for each student as an individual with his/her own special aptitude and interest, goal of helping each student to think for himself, and allowing the individuality to each learner. It's easy for piano instructors to overlook how intimidating learning the piano may be for a beginner. A youngster must not only acquire broad music aspects such as pitch, rhythm, phrasing, melody, and harmony, but also the particular of her instrument. If the instructor employs a conventional technique, the student will be expected to learn how to read music within a short period of time. A kid is required to read a written sign to inform her which of the eighty-eight keys she sees before playing, which hand and finger to use, how long to hold the note, and how loud or quiet that note is. This is just for one note; in order to finish a piece or even a phrase, the youngster must make these judgments many times. As the youngster grows, she is expected to read the music fluently, use both hands individually and concurrently, and use her foot to pedal the melodic phrases she is attempting to create from the individual notes she sees before her. This is just a synopsis of what a youngster needs to learn in order to play the piano fluently. As stated before in the section under "Cognitive and Physical Requirements of Skilled Pianists and Musicians," a person's mental perception and picture of the music influences how they play. It is a kind of mental perception when a youngster understands how a tune should sound since she has heard it before. This prior understanding of a song helps the youngster to "self-correct" and compare her performance. This demonstrates how important it is for the learner to have a comparable example. When feasible, the instructor should present this example.

\subsubsection{Language/terminologies employed}

Table 2 Language/terminologies employed

\begin{tabular}{|l|l|l|}
\hline LANGUAGE/TERMINOLOGIES EMPLOYED & Mean & $\begin{array}{l}\text { Verbal } \\
\text { Interpretation }\end{array}$ \\
\hline 1. The language use is confusing or too deep & 3.54 & Strongly Agree \\
\hline 2. The language use are not easily understandable & 3.65 & Strongly Agree \\
\hline 3. The language used is something I am not very familiar with & 3.68 & Strongly Agree \\
\hline 4. The language seemed to be not appropriate with the lesson & 3.54 & Strongly Agree \\
\hline 5. There is an excessive use of native language & 3.73 & Strongly Agree \\
\hline TOTAL & $\mathbf{3 . 6 3}$ & Strongly Agree \\
\hline
\end{tabular}

3.25-4.00 Strongly Agree; 2.50-3.24 Agree; 1.75-2.49 Disagree; 1.00-1.74

Table 2 represents the assessment of the challenges in modular learning in terms of language/terminologies employed. It shows that they are strongly agreed on the statements above with a weighted mean of 3.63 .

The language and terminologies are always believed to play a central role in learning through piano lessons. No matter what the subject area, students assimilate new concepts when they listen, talk, read and write about what they are learning. Speaking and writing reflects the thinking process that is taking place. Although most students will not be required to perform a piece without auditory feedback, it is crucial to recognize that students get reliant on their feedback expectations. One example of how this anticipated feedback might be damaging is a child's out-of-tune piano at home. Without even recognizing it, the youngster develops a taste for her compositions when played on an out-of-tune piano. When she comes to lessons and performs the piece on a tuned piano, she may grow irritated. This research seems to suggest that older children have a more difficult time adjusting to diverse situations due to their expectations. It is vital to remember that children are still physically growing at the age of five. Motor movement is classified into two types: gross and fine. Gross motor abilities need the use of the whole body or limb (s). Fine motor abilities are often performed using the fingers or hands.

\subsubsection{Content}

\section{Table 3 Content}

\begin{tabular}{|l|l|l|}
\hline CONTENT & Mean & $\begin{array}{l}\text { Verbal } \\
\text { Interpretation }\end{array}$ \\
\hline 1. The content of the piano lessons are vague & 3.43 & Strongly Agree \\
\hline 2. The content of the piano lessons are not arranged chronologically & 3.52 & Strongly Agree \\
\hline $\begin{array}{l}\text { 3. The content of the piano lessons seemed to be irrelevant with one } \\
\text { another }\end{array}$ & 3.58 & Strongly Agree \\
\hline
\end{tabular}




\begin{tabular}{|l|l|l|}
\hline $\begin{array}{l}\text { 4. The content of the piano lessons has many typographical errors, } \\
\text { mistakes, etc. }\end{array}$ & 3.41 & Strongly Agree \\
\hline 5. The content of the piano lessons is too much or overwhelming & 3.65 & Strongly Agree \\
\hline TOTAL & $\mathbf{3 . 5 2}$ & Strongly Agree \\
\hline
\end{tabular}

3.25-4.00 Strongly Agree; 2.50-3.24 Agree; 1.75-2.49 Disagree; 1.00-1.74

Table 3 represents the assessment of the challenges in modular learning in terms of content. It shows that they are strongly agreed on the statements above with a weighted mean of 3.52.

Piano lessons must concisely and clearly describes the session contents. Piano lessons should focus on providing context. When completed, their piano lessons introductions will help highlight the narrative arc of their course: how each piano lesson builds toward those after it and how each serves a vital role in the students' achievement of the course objectives. A study conducted by Peter and Elizabeth Ann Wolff examined the relationship between motor and verbal activity in children and discovered that good gross motor abilities were associated with the quantity of speech, whereas good fine motor skills were associated with the quality or sophistication of a child's speech. Learning an instrument, such as the piano, is often seen as a fine motor skill, although it does need both. The fingers have just a limited amount of power and strength. A pianist must be able to utilize his whole arm while also being aware that it is related to the rest of his body. While a kid may come to a music instructor with a preference for gross or fine motor abilities, it is critical to recognize that the child must learn to be proficient in all areas. Judy L. Kerchner performed a study that connected how children communicate their knowledge of a piece of music in three distinct formats: verbal, visual, and kinesthetic, comparing the reactions of second and fifth graders during and after listening to J. S. Bach's Brandenburg Concerto No. 2 in F. The pupils were able to evaluate and compare the spoken replies.

\subsubsection{Evaluation activities}

Table 4 Evaluation activities

\begin{tabular}{|l|l|l|}
\hline EVALUATION ACTIVITIES & Mean & $\begin{array}{l}\text { Verbal } \\
\text { Interpretation }\end{array}$ \\
\hline 1. The evaluation activities are not easily achievable & 3.82 & Strongly Agree \\
\hline 2. The evaluation activities are too hard & 3.84 & Strongly Agree \\
\hline 3. The evaluation activities are too easy or simple & 3.35 & Strongly Agree \\
\hline 4. The evaluation activities included are easily searchable in the Internet & 3.43 & Strongly Agree \\
\hline 5. There are no evaluation activities included & 3.37 & Strongly Agree \\
\hline TOTAL & $\mathbf{3 . 5 6}$ & Strongly Agree \\
\hline
\end{tabular}

3.25-4.00 Strongly Agree; 2.50-3.24 Agree; 1.75-2.49 Disagree; 1.00-1.74

Table 4 represents the assessment of the challenges in modular learning in terms of evaluation activities. It shows that they are strongly agreed on the statements above with a weighted mean of 3.56.

Challenges arose due to the impact of physical distance between the instructor and the students, adaptations resulting from the necessity of using technology for communicating with students, workload and time management issues, and the ongoing need to collect a variety of assessment data and provide feedback.

To describe the music, the children often coined new terms. Second graders tended to concentrate on the music's wide scale, particularly on the instrumental timbres and referential connections they formed with it. The fifth graders were more interested in a broader variety of themes, and "whereas the second graders identified instruments, the fifth students explained how the instrumental sections linked to each other" (texture). They also explained the performance procedure and the talent necessary to play the musical instruments." The visual responses of the children were images or maps created by the kids while listening. "The approach allowed students in both grades to portray more information than they could in the verbal response mode, notably in their descriptions of musical texture, beat, ornamentation, shape, contour, melodic rhythm, and length." Second students used more visuals, while fifth graders used more words. When the listening was repeated, children in both grades experienced "difficulties retracing and recreating." The students sometimes went from one part of their graph to the next, rather than following the continuous line of the graphs as they had created them."

While some children's kinesthetic responses included a wealth of information, they did not lend themselves to musical expression. The youngsters that could communicate themselves kinesthetically were outliers, which meant they were uncommon. These outliers moved in a variety of ways: one used his hands and sometimes danced, another choreographed a gymnastics routine, and two pretended to lead the orchestra. These kids were outliers because "they picked continuous motion that allowed them 
to respond, consciously or subconsciously, to musical events as they evolved." Their motions included a wealth of musical information that they did not explicitly explain." Three of the four youngsters were in fifth grade. Kerchner did not include singing as part of the verbal component, despite the fact that over half of the youngsters sang while describing the music. "The students sought to vocally articulate rhythmic and/or melodic characteristics of the core subject material, and singing was used often." When one student "found it difficult to find the suitable name for the shrill flute' (trumpet trill), he utilized his voice to convey the fluttering sound of the trill."

\subsection{Significant relationship in the assessing the preschool piano educator's comprehensive capacity development in the era of intelligent keyboards when grouped according to profile}

Table 5. Significant relationship in the assessing the preschool piano educator's comprehensive capacity development in the era of intelligent keyboards and its age.

\begin{tabular}{|l|c|c|c|c|c|}
\hline Components & $\begin{array}{l}\text { Chi-Square } \\
\left(\mathbf{x}^{\mathbf{2}}\right)\end{array}$ & df & p-value & Decision & Remarks \\
\hline Understanding of objectives & 3.091 & 4 & .438 & $\begin{array}{c}\text { Fail to } \\
\text { Reject Ho }\end{array}$ & $\begin{array}{c}\text { Not } \\
\text { Significant }\end{array}$ \\
\hline Language/Terminologies & 5.981 & 4 & .165 & $\begin{array}{c}\text { Fail to } \\
\text { Reject Ho }\end{array}$ & $\begin{array}{c}\text { Not } \\
\text { Significant }\end{array}$ \\
\hline Content & 2.431 & 4 & .218 & $\begin{array}{c}\text { Fail to } \\
\text { Reject Ho }\end{array}$ & $\begin{array}{c}\text { Not } \\
\text { Significant }\end{array}$ \\
\hline Evaluation Activities & 4.076 & 4 & .462 & $\begin{array}{c}\text { Fail to } \\
\text { Reject Ho }\end{array}$ & $\begin{array}{c}\text { Not } \\
\text { Significant }\end{array}$ \\
\hline
\end{tabular}

Table 5 demonstrated a significant relationship between the assessment of the participants on the challenges in modular learning and its age based on understanding of objectives $(\operatorname{sig}=. .438>0.05)$, language/terminologies (sig=.165>0.05), content $(\mathrm{sig}=.218>0.05)$, and evaluation activities (sig=.462>0.05). It shows that there is no significant relationship between the assessment of the participants on the challenges in modular learning and its age.

The most crucial finding in that research was that all of the youngsters compared the Brandenburg Concerto to music they were acquainted with from other sources. This insight is significant for instructors because it should influence the way we introduce music to our pupils. When instructors introduce new pieces, styles, periods, or genres of music to their pupils, they should relate them to notions they are already acquainted with. This is also why instructors should encourage their kids to listen to a variety of music. Everyone has had the sensation of having a song "stuck in your brain," causing them to sing or hum it again and over. Evidence suggests that when children are acquainted with tunes, they are better able to execute them. The capacity to notice mistakes is essential while learning to perform music. Because the majority of learning in private study is done via self-study or practice, it is critical that a kid be able to self-correct. Alfredo Bautista et al. discovered five distinct categories of how piano students interpret music notation in a study of piano students' ideas of music scores: (1) "Musical scores as a set of symbols to be processed" (2) "Musical scores are collections of to-be-solved technological issues," (3) "Musical scores are exterior representations that are beginning to be seen as having an interior grammar," (4) "Musical scores as syntactically understandable, performable, and communicable external representations," (5) "Musical scores are exterior representations that may also be studied in their whole."

These classes are listed in increasing complexity order. This research primarily focused on kids aged twelve and above, although it is interesting to note that the majority of pupils aged twelve to fourteen was in the first categorization. 64 Because these classes were arranged in ascending order of difficulty, pupils aged five to ten may be presumed to be in the same classification as students aged twelve to fourteen. For most ordinary primary pupils, music notation would be seen as a collection of symbols that must be processed. To comprehend any form of sign, the pupil must be able to retain and recall the meaning of each symbol. Siu-Lan Tan discovered that adult novices had logical errors about music notation in a research on beginner's intuitions about musical notation. The author's conclusion is useful when dealing with very young kids. It is important to "pay particular attention to the terminology, images, metaphors, and even gestures that beginning students employ," as this "may provide instructors hints about how their pupils are making sense of the symbols and laws of music." 66 It may not be the ideal way to ask a youngster what they believe a sign represents since it may foster the formation of false interpretations. "One reason why starting students may make the same mistakes is because they are oscillating between their first intuitions about what symbols could signify and the customarily 
'proper' interpretations (which may be counter-intuitive to them)."

Table 6. Significant relationship in the assessing the preschool piano educator's comprehensive capacity development in the era of intelligent keyboards and its gender.

\begin{tabular}{|l|c|c|c|c|c|}
\hline Components & $\begin{array}{l}\text { Chi-Square } \\
\left(\mathbf{x}^{\mathbf{2}}\right)\end{array}$ & $\mathbf{d f}$ & $\mathbf{p}$-value & Decision & Remarks \\
\hline Understanding of objectives & 3.910 & 1 & .342 & $\begin{array}{c}\text { Fail to } \\
\text { Reject Ho }\end{array}$ & $\begin{array}{c}\text { Not } \\
\text { Significant }\end{array}$ \\
\hline Language/Terminologies & 2.972 & 1 & .651 & $\begin{array}{c}\text { Fail to } \\
\text { Reject Ho }\end{array}$ & $\begin{array}{c}\text { Not } \\
\text { Significant }\end{array}$ \\
\hline Content & 2.991 & 1 & .339 & $\begin{array}{c}\text { Fail to } \\
\text { Reject Ho }\end{array}$ & $\begin{array}{c}\text { Not } \\
\text { Significant }\end{array}$ \\
\hline Evaluation Activities & 2.001 & 1 & .581 & $\begin{array}{c}\text { Fail to } \\
\text { Reject Ho }\end{array}$ & $\begin{array}{c}\text { Not } \\
\text { Significant }\end{array}$ \\
\hline
\end{tabular}

Table 6 demonstrated a significant relationship between the assessment of the participants on the challenges in modular learning and its gender based on understanding of objectives (sig=..342>0.05), language/terminologies $(\mathrm{sig}=.651>0.05)$, content $(\mathrm{sig}=.339>0.05)$, and evaluation activities $(\mathrm{sig}=.581>0.05)$. It shows that there is no significant relationship between the assessment of the participants on the challenges in modular learning and its gender.

Playing any keyboard instrument involves significant cognitive and biomechanical demands on the player, and as a result, psychologists and musicologists have long been interested in researching the motions of pianists. Otto Ortmann investigated the mechanics of piano playing in the 1920s from the viewpoints of the instrument (Ortmann 1925) and the player's body (Ortmann 1929). Recent research has looked on the specifics of finger motion as it pertains to tempo and timing accuracy. The force between the finger and the key has been researched in terms of dynamic level (Kinoshita et al. 2007) and movement efficiency. Other studies have looked at the kinematics of the hand, the upper limbs (Furuya and Kinoshita 2008), and the torso and head (Furuya and Kinoshita 2008). Expert pianists and amateurs are frequently compared in studies, with experts demonstrating better use of the innate connectivity between fingers more economical use of finger force and more efficient coordination of upper limb motion. Metcalf et al. reported a further assessment of the biomechanics of musical performance (2014). The acoustic piano's basic discreteness has long been a source of contention: Is it feasible to change the sound of a piano note irrespective of its loudness? Hart, Fuller, and Lusby (1934) demonstrated that the velocity of hammer-string collisions was solely responsible for a note's sound: every change in tone was followed by a change in loudness, and vice versa. Despite this, pianists often describe their touch in sophisticated, multidimensional ways that extend well beyond this basic velocity-based approach.

Table 7. Significant relationship in the assessing the preschool piano educator's comprehensive capacity development in the era of intelligent keyboards and its educational background.

\begin{tabular}{|l|c|c|c|c|c|}
\hline Components & $\begin{array}{c}\text { Chi- } \\
\text { Square } \\
\left(\mathbf{x}^{2}\right)\end{array}$ & df & p-value & Decision & Remarks \\
\hline $\begin{array}{l}\text { Understanding of } \\
\text { objectives }\end{array}$ & 4.116 & 4 & .763 & $\begin{array}{c}\text { Fail to } \\
\text { Reject Ho }\end{array}$ & $\begin{array}{c}\text { Not } \\
\text { Significant }\end{array}$ \\
\hline Language/Terminologies & 5.907 & 4 & .348 & $\begin{array}{c}\text { Fail to } \\
\text { Reject Ho }\end{array}$ & $\begin{array}{c}\text { Not } \\
\text { Significant }\end{array}$ \\
\hline Content & 3.009 & 4 & .653 & $\begin{array}{c}\text { Fail to } \\
\text { Reject Ho }\end{array}$ & $\begin{array}{c}\text { Not } \\
\text { Significant }\end{array}$ \\
\hline Evaluation Activities & 2.896 & 4 & .562 & $\begin{array}{c}\text { Fail to } \\
\text { Reject Ho }\end{array}$ & $\begin{array}{c}\text { Not } \\
\text { Significant }\end{array}$ \\
\hline
\end{tabular}

Table 7 demonstrated a significant relationship between the assessment of the participants on the challenges in modular learning and its educational background based on understanding of objectives $(\mathrm{sig}=. .763>0.05)$, language/terminologies $(\mathrm{sig}=.348>0.05)$, content $(\mathrm{sig}=.653>0.05)$, and evaluation activities $(\mathrm{sig}=.562>0.05)$. It shows that there is no significant relationship between the assessment of the participants on the challenges in modular learning and its educational background.

Touch's musical significance may be explained in part by its influence on the time and velocities of larger musical phrases. Goebl, Bresin, and Fujinaga (2014) demonstrated that supplemental impact sounds between finger and key or key and key bed alter the perception of a single tone and enable a listener to distinguish between pushed (non-percussive) and striking (percussive) touches. In prior 
research discovered that, independent of acoustic effects, a pianist may regulate the continuous motion of the key in numerous simultaneous dimensions other than velocity. Percussiveness, weight, and depth are among these dimensions. Bernays and Traube (2014) discovered significant differences in continuous key motion profiles among four pianists, depending on both individual style and desired timbre in performance. These research give instrument designers reason to be both optimistic and cautious. Even on fundamentally discrete instruments, keyboard technique consists of meaningful, repeatable patterns of continuous action that may be altered for different musical goals. At the same time, because of the intricacy of current keyboard practice, any new continuous controls should be introduced with caution to prevent overburdening the performer.

Table 8. Significant relationship in the assessing the preschool piano educator's comprehensive capacity development in the era of intelligent keyboards and its length of teaching experiences.

\begin{tabular}{|l|c|c|c|c|c|}
\hline Components & $\begin{array}{c}\text { Chi-Square } \\
\left(\mathbf{x}^{\mathbf{2}}\right)\end{array}$ & df & p-value & Decision & Remarks \\
\hline $\begin{array}{l}\text { Understanding of } \\
\text { objectives }\end{array}$ & 3.123 & 4 & .127 & $\begin{array}{c}\text { Fail to } \\
\text { Reject Ho }\end{array}$ & Not Significant \\
\hline Language/Terminologies & 2.416 & 4 & .521 & $\begin{array}{c}\text { Fail to } \\
\text { Reject Ho }\end{array}$ & Not Significant \\
\hline Content & 4.642 & 4 & .381 & $\begin{array}{c}\text { Fail to } \\
\text { Reject Ho }\end{array}$ & Not Significant \\
\hline Evaluation Activities & 3.133 & 4 & .493 & $\begin{array}{c}\text { Fail to } \\
\text { Reject Ho }\end{array}$ & Not Significant \\
\hline
\end{tabular}

Table 8 demonstrated a significant relationship between the assessment of the participants on the challenges in modular learning and their length of teaching experiences based on understanding of objectives ( $\operatorname{sig}=. .127>0.05)$, language/terminologies $(\operatorname{sig}=.521>0.05)$, content $(\operatorname{sig}=.381>0.05)$, and evaluation activities $(\mathrm{sig}=.493>0.05)$. It shows that there is no significant relationship between the assessment of the participants on the challenges in modular learning and their length of teaching experiences.

Before delving into individual instruments, it's important to understand how a keyboard may be characterized as continuous or discrete. I'll ignore the complicated problem of phrasing over subsequent notes in order to focus on three qualities of a single note: onset, sustain, and release. The short interval when the note starts is referred to as the onset. Though velocity (dynamic control) is the most wellknown aspect of piano note onset, it is merely one aspect of the larger quality of articulation. The many note onsets conceivable on bowed string instruments demonstrate that there is still much to be discovered in this field (for an overview of string articulations, On mechanical tracker organs, for example, the speed of key onset offers control over the early transients when the pipe speaks. Another example is the famous Hammond B3 organ, which has nine electrical connectors on each note, one for each drawbar.

This method was responsible for the "key click" sound that musicians learned to appreciate; in reality, the duration and loudness of the click may be subtly changed by changing the speed of the key, causing various drawbars to engage at slightly different times. These effects were regarded significant enough that the Hammond B3's digital reproduction in 2003 reproduced the original multi-contact keyboard. Further note articulation options will be discussed in the TouchKeys section later in this paper. Sustain is the midway note between onset and release. The term "continuous control" is often used in the instrument design literature to refer to the capacity to modify the sustain of a note, altering its pitch, loudness, or timbre. The capacity to adjust dynamics or add vibrato from the keyboard, in particular, has long been a source of inspiration for designers. This article will concentrate on how to shape a note's sustain from the keyboard alone, ignoring any other controls (e.g., the organ swell pedal or the synthesizer pitch wheel). Release may be as easy as suddenly ceasing a note, but there are more options. Surprisingly, the acoustic piano keyboard allows for continuous control upon release since the damper may be brought into contact with the string gradually or suddenly. Other melodic options on note release suggested by jazz brass instrument technique include falls (pitch drop on release) and doits (upward glissando on release). This article's TouchKeys section will look at how these concepts may be used to a keyboard.

Following the invention of the Moog Multiply Touch-Sensitive keyboard in the 1970s and 1980s, various new devices using continuous measurement have been built. Freed and Avizienis (2000) developed a keyboard controller that could transmit data through a digital audio or Ethernet connection and measured the continuous angle of each key. My TouchKeys technology introduced capacitive 
touch sensing to the key surface, allowing for two-dimensional assessment of each finger position. This technology, which will be covered in more detail later in this article, is intended to be attached to any current keyboard. Data from each dimension may be mapped to MIDI or Open Sound Control (OSC) signals in a variety of ways. Capacitive sensing is also used in Jeff Snyder's JD-1 synthesizer controller, which measures the continuous contact area of the fingers on fixed metal keys. The Endeavour EVO (Kirn, 2012), which used capacitive sensing on one axis to measure finger position along a portion of the key, and the Keith McMillen QuNexus (www.keithmcmillen.com/qunexus), a miniature pressure pad controller in a keyboard layout with polyphonic after touch, are recent commercial examples. Pressure pads that detect tilt in two dimensions are included in Roger Linn's Instrument (www.rogerlinndesign.com/linnstrument.html), the Keith McMillen QuNeo (www.keithmcmillen.com/QuNeo), and the Eigen Labs Eigenharp (www.eigenlabs.com). Some instruments have gone one step farther by replacing separate keys with a single continuous control surface.

The Continuum Fingerboard (Haken, Tellman, and Wolfe 1998) by Lippold Haken provides the performer with a continuous pressure-sensitive control surface that monitors each finger's threedimensional location. The horizontal axis is often used to adjust pitch, and printed patterns on the surface show where the black and white notes may be located. The ROLI Seaboard (Lamb and Robertson 2011) likewise employs a continuous pressure-sensitive control surface in the form of raised "keywaves" imitating the black and white keys. The Continuum and Seaboard both let the musician to move between notes by dragging a finger horizontally. To overcome the difficulty of beginning a note in tune on a continuous surface, both instruments offer choices for guiding the starting pitch toward the closest semitone. The demand for greater pitch control has also led to the creation of microtonal keyboards (Keislar 1987) with more than 12 keys per octave, but each key is often an independent control (onset and release only).

\section{Conclusion}

1) The piano educators were in a suitable age in teaching, primarily female, have bachelor's degree and have vast years in teaching as their profession.

2) Piano educators encounter different challenges in the implementation of teaching piano lessons in learning modality of the preschool.

3) There is no significant relationship between the assessing the preschool piano educator's comprehensive capacity development in the era of intelligent keyboards and when grouped according to profile

\section{Recommendations}

1) Department of Education should implement a system in terms of delivery and retrieval of piano lessons to ensure that both parents and piano educators are aware of what to do as well as to keep everyone safe from the effects of the COVID-19 pandemic.

2) Piano educators should practice the time management, innovating teaching strategies, are some of the ways on how piano educators cope with the challenges that they encounter in teaching piano lessons.

3) Students should adapt to the changes brought by the new normal trend in education, being flexible, providing alternative plans, being optimistic and patient, and equipping oneself with the necessary skills

4) Parents should give full support for their children in adapting new normal trend in education.

5) Researcher should create more substantial and more effective factual based recommendations that would address the gaps, concerns and/or issues found during the analysis and/or interpretation of data.

6) Future Researchers should recommend that further studies on the current situation of piano educators in the implementation of new normal education be conducted.

\section{References}

[1] Aamodt, Sandra and Sam Wang. Welcome to your Child's Brain. New York: Bloomsbury, 2011. Bautista, Alfredo, Ma Del Put Perez Echeverria, J. Ignaclo Pozo, and Barbara M. Brizuela. "Piano Students' Conceptions of Musical Scores as External Representations: A Cross-Sectional Study." 
Journal of Research in Music Education 57, no.3 (2009): 181-202. http://0www.jstor.org.library.cedarville.edu/stable/40343726.

[2] Bernays, M., and C. Traube. 2014. "Investigating Pianists' Individuality in the Performance of Five Timbral Nuances through Patterns of Articulation, Touch, Dynamics, and Pedaling." Frontiers in Psychology 5. Available online at www.ncbi.nlm.nih.gov/pmc larticles/PMC3941302. Accessed November 2014.

[3] Brown, J.D. (1980) Identifying problems facing the school band movement. Elkhart: Gemeinhardt Co. Ltd

[4] Brown, J.D. (1985) Strategic marketing for music educators. Elkhart: Gemeinhardt Co. Ltd

[5] Clift, S. \& Hancox, G. (2001) 'The perceived benefits of singing: Findings from preliminary surveys of a university college choral society'. The Journal of the Royal Society for the Promotion of Health, 121(4), 248-256.

[6] Colwell, Richard, and Peter R. Webster, eds., MENC Handbook of Research on Music Learning. Vol. 1, Strategies. Oxford: Oxford University Press, 2011. —. MENC Handbook of Research on Music Learning. Vol. 2, Applications. Oxford: Oxford University Press, 2011.

[7] Colwell, Richard, ed., MENC Handbook of Musical Cognition and Development. Oxford: Oxford University Press, 2006.

[8] Covington, Kate. "The Mind's Ear: I Hear Music and No One is Performing." College Music Symposium 24 (2005): 25-41. http://www.jstor.org/stable/40374518.

[9] Freed, A., and R. Avizienis. 2000. "A New Music Keyboard Featuring Continuous Key-Position Sensing and HighSpeed Communication Options." In Proceedings of the International Computer Music Conference, pp. 515-516.

[10] Frewen, Katherine Goins. "Effects of Familiarity with a Melody Prior to Instruction on Children's Piano Performance Accuracy." Journal of Research in Music Education 57, no.4 (2010): 320-333. http://0- www.jstor.org.library.cedarville.edu/stable/40666499.

[11] Furuya, S., and H. Kinoshita. 2008. "Organization of the Upper Limb Movement for Piano KeyDepression Differs between Expert Pianists and Novice Players." Experimental Brain Research 185(4):581-593.

[12] Goebl, W., R. Bresin, and I. Fujinaga. 2014. "Perception of Touch Quality in Piano Tones." Journal of the Acoustical Society of America 136(5):2839-2850.

[13] Habib, Michel, and Mireille Besson. "What do Music Training and Musical Experience Teach Us About Brain Plasticity?” Music Perception: An Interdisciplinary Journal 26, no. 3 (2009): 279-285. http://www.jstor.org/stable/10.1525/mp.2009.26.3.279.

[14] Haken, L., E. Tellman, and P. Wolfe. 1998. “An Indiscrete Music Keyboard.” Computer Music Journal 22(1):30-48.

[15] Hallam, S., \& Prince, V. (2000). Research into instrumental music services. (London, DfEE).

Halsband, Ulrike, Ferdinand Binkosfski, and Max Camp. "The Role of the Perception of Rhythmic Grouping in Musical Performance: Evidence from Motor-Skill Development in Piano Playing. " Music Perception: An Interdisciplinary Journal 11, no.3 (1994): 265-288. http://www.jstor.org/stable/40285623.

[16] Hart, H. C., M. W. Fuller, and W. S. Lusby. 1934. "A Precision Study of Piano Touch and Tone." Journal of the Acoustical Society of America 6(2):80-94.

[17] Hayward, Coral M., and Joyce Eastlund Gromko. "Relationships among Music SightReading and Technical Proficiency, Spatial Visualization, and Aural Discrimination. ” Journal of Research in Music Education 57, no. 1 (2009): 26-36. http://www.jstor.org/stable/40204946.

[18] Karni, Avi, and Gundela Meyer, Christine Rey-Hipolito, et al. "The Acquisition of Skilled Motor Performance: Fast and Slow Experience-Driven Changes in Primary Motor Cortex." Proceedings of National Academy of Sciences of the 28 United States of America 95, no. 3 (1998): 861-868. http://0www.jstor.org.library.cedarville.edu/stable/44200.

[19] Keislar, D. 1987. "History and Principles of Microtonal Keyboards." Computer Music Journal 11(1):18-28.

[20] Kerchner, Jody L. "Children's Verbal, Visual, and Kinesthetic Responses: Insight into Their Music Listening Experience.” Bulletin of the Council for Research in Music Education no. 145 (2000): 31-50. http://0-www.jstor.org.library.cedarville.edu/stable/40319032.

[21] Kinoshita, H., et al. 2007. "Loudness Control in Pianists as Exemplified in Keystroke Force Measurements on Different Touches. ” Journal of the Acoustical Society of America 121(5):2959-2969.

[22] Kirn, P. 2012. “Endeavour's Evo, Touch-Sensitive Keyboard, Reimagined.” Create Ditigal Music. Available online at createdigitalmusic.com/2012 /11/endeavours-evo-touch-sensitive-keyboard reimagined-now-from-eur499-gallery-videos. AccessedNovember 2014.

[23] Leohr, Janeen D., and Caroline Palmer. "Subdividing the Beat: Auditory and Motor 
Contributions to Synchronization." Music Perception: An Interdisciplinary Journal 26, no.5 (2009): 415-425. http://www.jstor.org.library.cedarville.edu/stable/10.1525/mp.2009.26.5.415.

[24] Madell, Jaime and Sylvie Hébert. "Eye Movements and Music Reading: Where Do We Look Next?" Music Perception: An Interdisciplinary Journal 26, no. 2 (December 2008): 157-170. http://www.jstor.org/stable/10.1525/mp.2008.26.2.157.

[25] Marshall, A.T. (1978) An analysis of music curricula an its relationship to the self image of urban black middle school age children: Dissertation Abstracts International, A 38, 6594A5A

[26] North, A.C., Hargreaves, D.J. and O'Neill, S.A. (2000) 'The importance of music to adolescents'. British Journal of Educational Psychology, 70, 255-272.

[27] Overy, Katie and Istvan Molnar-Szakacs. "Being Together in Time: Musical Experience and the Mirror Neuron System." Music Perception: An Interdisciplinary Journal 26, no.5 (2009): 489-504. http://Owww.jstor.org.library.cedarville.edu/stable/10.1525/mp.2009.26.5.489.

[28] Ristad, Eloise. A Soprano on Her Head: Right-Side-Up Reflections on Life and Other Performances. Utah: Real People Press, 1982.

[29] Rose, F. Clifford, ed. Neurology of Music. London: Imperial College Press, 2010.

[30] Sergent, Justine, Eric Zuck, Sean Terriah, and Brennan MacDonalk. "Distributed Neural Network Underlying Musical Sight-Reading and Keyboard Performance.” Science 257, no. 5066 (1992): 105 109. http://www.jstor.org/stable/2877445.

[31] Siu-Lan Tan. “Beginners' Intuitions about Musical Notation.” College Music Symposium 42 (2002): 131-141. http://0- www.jstor.org.library.cedarville.edu/stable/40374428.

[32] Spychiger, M., Patry, J. Lauper, G., Zimmerman, E., \& Weber, E. (1993). 'Does more music teaching lead to a better social climate'. In R. Olechowski \& G. Svik (eds) Experimentalnresearch in teaching and learning. (Bern, Peter Lang).

[33] Spychiger, M., Patry, J. Lauper, G., Zimmerman, E., \& Weber, E. (1993). 'Does more musicnteaching lead to a better social climate'. In R. Olechowski \& G. Svik (eds) Experimental research in teaching and learning. (Bern, Peter Lang).

[34] Stecher, Mariam B., and Hugh McElheny. Joy and Learning through Music and Movement Improvisations. New York: Macmillan Publishing Co., Inc., 1972.

[35] Stinson, William J., ed. Moving and Learning for the Young Child. Reston: American Alliance for Health, Physical Education, Recreation, and Dance, 1990.

[36] Westney, William. The Perfect Wrong Note: Learning to Trust Your Musical Self. New Jersey: Amadeus Press, 2006. 29

[37] Whitwell, D. (1977) Music learning through performance. Texas: Texas Music Educators Association.

[38] Wolff, Peter, and Elizabeth Ann Wolff. "Correlational Analysis of Motor and Verbal Activity in Young Children." Child Development 43, no. 4 (1972): 1407-1411. http://0www.jstor.org.library.cedarville.edu/stable/1127526.

[39] Zimmerman, Marilyn Pflederer. "Music Development in Middle Childhood: A Summary of Selected Research Studies." Bulletin of the Council for Research in Music Education no. 86, (1986): 18-35. http://www.jstor.org/stable/40317966. 